\title{
Cervicofacial Emphysema and Pneumomediastinum Complicating a Dental Extraction
}

\author{
Abdelkarim Shimi, Said Benlamkaddem, Driss Tahse, Ali Derkaoui, Mohammed Khatouf \\ Intensive Care Unit A1, University Hospital Hassan II, Sidi Mohamed Ben Abdellah University, Fez, Morocco \\ Email: akshimi@gmail.com
}

Received 22 May 2015; accepted 4 July 2015; published 7 July 2015

Copyright (C) 2015 by authors and Scientific Research Publishing Inc. This work is licensed under the Creative Commons Attribution International License (CC BY). http://creativecommons.org/licenses/by/4.0/ (c) (i) Open Access

\begin{abstract}
Background: Pneumomediastinum and subcutaneous emphysema are a rare and well-known complication of dental procedures. Many cases go unrecognized and resolve spontaneously, while others may require specific therapeutic management to prevent complications. Case Presentations: We report a case of cervical subcutaneous emphysema and pneumomediasitnum occurring after extraction of lower right second molar. The emphysema was detected 2 hours after dental surgery. This paper reports on the diagnosis and treatment of subcutaneous emphysema and pneumomediastinum. Conclusion: In order to prevent this complication, air turbine high speed drills should be used only in necessary cases.
\end{abstract}

\section{Keywords}

Subcutaneous Emphysema, Pneumomediastinum, Dental Extraction

\section{Introduction}

Cervicofacial subcutaneous emphysema and pneumomediastinum are defined as the abnormal introduction of air in the subcutaneous tissues of the head and neck. The condition can be caused by a traumatic injury or by increased pressure within the lungs or airways such as excessive coughing, vomiting, or repeated bearing down to increase abdominal pressure during delivery or severe constipation [1]. Spontaneous pneumomediastinum may also complicate obstructive airway processes such as asthma or foreign bodies [2].

The occurrence of subcutaneous emphysema after dental treatment is rare, and diffusion of gas into the mediastinum is much rarer, especially when the procedure is a non surgical treatment. The most common dental cause of pneumomediastinum is the introduction of air via the air turbine handpiece during surgical extraction of 
an impacted tooth [3].

We report a case of cervicofacial emphysema and pneumomediastinum occurring after extraction of a mandibular right second molar using an air turbine drill. The emphysema was detected two hours after dental extraction. This papers reports on the diagnosis and treatment of cervicofacial emphysema and pneumomediastinum.

\section{Case Presentation}

A 17-year-old female with no clinical history of interest was referred to the emergency department with a history of central chest pain, bilateral neck swelling and dyspnea. Two hours before she had undergone a lower right second molar surgical extraction under local anesthesia by a general dental practitioner.

On examination her pulse was $84 / \mathrm{mn}$, blood pressure 135/70 $\mathrm{mmHg}$, respiratory rate 20/mn, temperature $37.1^{\circ} \mathrm{C}$ and maintaining oxygen saturation $100 \%$. Examination revealed a bilateral neck swelling, with crepitus on palpation suggesting deep surgical emphysema.

Computerized tomography of the neck thorax region showed significant air accumulation involving the prevertebral area, retropharyngeal area, mediastinum, and subcutaneous tissue of the neck (Figure 1). The diagnosis was massive pneumomediastinum and cervico-facial emphysema complicating a dental extraction.

The patient was hospitalized for intravenous antibiotic therapy and monitoring. She was treated with intravenous ceftriaxone $2 \mathrm{~g} / 24 \mathrm{H}$ and analgesics as required. The swelling and the subcutaneous emphysema subsided within 4 days. During this period the patient did not experience any airway obstruction. She was discharged from the hospital 4 days later and continued the oral antibiotic therapy for 5 more days with no further complications.

\section{Discussion}

Cervical emphysema and peumomediastinum can be defined as the presence of air in subcutaneous soft tissue and mediastinum. This clinical condition is reported to be caused by a high-speed air-turbine dental drill or other pressured appliances used during dental procedures [4] [5]. These appliances can introduce the pressured air into the soft tissues. Especially in procedures involving molar teeth, air can diffuse the pterygomandibular region and lateral pharyngeal space from the retromolar region [6]. The presence of free air on the retropharyngeal space may lead to eustachian tube dysfunction and hearing loss, dysphonia and dysphagia [7]. The roots of molar teeth are connected with the submandibular space, which communicates with the retropharyngeal space and mediastinum. Air can also reach the retroperitoneum and pleural cavities. It is reported that subcutaneous emphysema and pneumomediastinum can also be seen after nose blowing [8].

Symptoms of pneumomediastinum and subcutaneous emphysema in the cervico-facial region can vary. In the medical literature we find descriptions of a variety of symptoms such as swelling, a sensation of fullness in the facial/cervical region, erythema, crepitus, dysphagia, dysphonia, dyspnea, periorbital swelling, emphysema around the eye, and pain [9] [10].
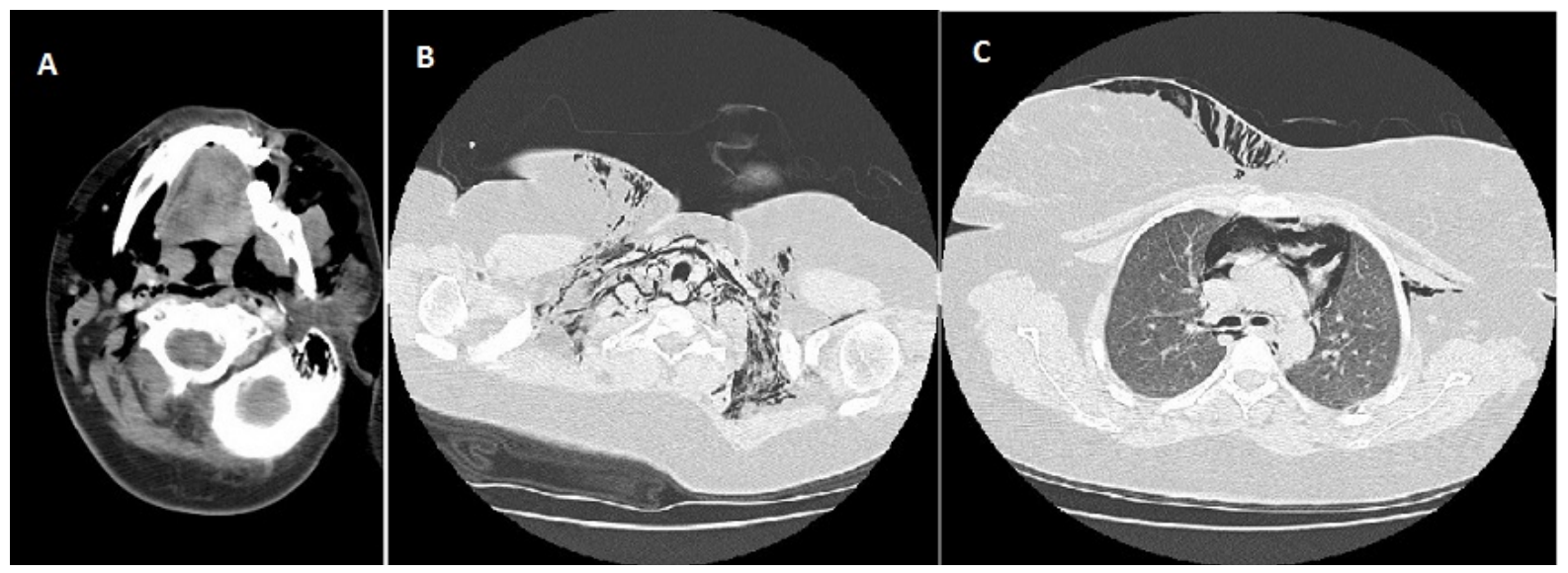

Figure 1. Computed tomography scan shows extensive air in the soft tissue of the neck and perimandibular/retropharyngeal regions (A). Massive air can be seen in the superior mediastinum (B) and lower mediastinum (C). 
The differential diagnosis of a rapid facial swelling following a dental procedure should take into consideration angioedema, hematoma, cellulites, allergic reaction and subcutaneous emphysema [11] [12]. Both crepitus and/or a plain film of the neck showing the presence of air trapped in the soft tissues are pathognomonic of subcutaneous emphysema. The existence of a pulsate mass or a bruit detected by a stethoscope can help to distinguish between a rapidly swelling hematoma and subcutaneous emphysema. A CT scan of the neck with contrast material provides an accurate diagnosis, leading to the right management of disorder [10]. In our case, injection of air with a high speed dental drill through the soft tissue adjacent to the inferior molar seemed to cause cervicofacial emphysema leading to pneumomediastinum. Medical literature also supports this as the most probable etiology [13] [14].

Treatment of pneumomediastinum is symptomatic, monitoring cardiac activity, respiration and providing appropriate antibiotics and analgesia. Prevention of air embolus is the primary concern, using sedatives to decrease excessive respiratory effort, stool softener to limit valsalva maneuver, anticough agents to suppress coughing, nasal decongestant and antihistaminic to suppress nose blowing. Smoking must be prohibited. Administration of $100 \%$ oxygen may be considered to increase the tendency of absorption of nitrogen by reducing its surrounding partial pressure.

A patient suffering from pneumomediastinum and cervicofacial emphysema who does not develop any complications can be discharged from the hospital following an observation period of $1-2$ days. The emphysema is likely to resolve fully within 1 or 2 weeks, depending on the initial amount of entrapped air [12].

\section{Conclusion}

Dentists should be aware that the use of air-driven handpieces or compressed air-syringes can lead to lifethreatening complications even in nonsurgical fields. They should always recognize the possibility of pneumomediastinum and emphysema after any dental treatment. In order to prevent this complication, air turbine high speed drills should be used only in necessary cases.

\section{Statement}

No potential conflict of interest relevant to this article were reported or known.

\section{References}

[1] Maunder, R.J., Pierson, D.J. and Hudson, L.D. (1984) Subcutaneous and Mediastinal Emphysema: Pathophysiology, Diagnosis and Management. Archives of Internal Medicine, 144, 1447-1453. http://dx.doi.org/10.1001/archinte.1984.00350190143024

[2] Dean, L.M. and Kuhns, L.R. (1992) Pneumomediastinum in an Unusual Location. American Journal of Roentgenology, 159, 900-901. http://dx.doi.org/10.2214/ajr.159.4.1529865

[3] Horowitz, I., Hirshberg, A. and Freedman, A. (1987) Pneumomediastinum and Emphysema Following Surgical Extraction of Mandibular Third Molars: Three Case Reports. Oral Surgery, 63, 25-28. http://dx.doi.org/10.1016/0030-4220(87)90335-5

[4] Monsour, P.A. and Savage, N.W. (1989) Cervicofacial Emphysema Following Dental Procedures. Australian Dental Journal, 34, 403-406. http://dx.doi.org/10.1111/j.1834-7819.1989.tb00695.x

[5] Szubin, L., La Bruna, A., Levine, J. and Komisar, A. (1997) Subcutaneous and Retropharyngeal Emphysema after Dental Procedures. Otolaryngology-Head and Neck Surgery, 117, 122-123. http://dx.doi.org/10.1016/S0194-5998(97)70219-5

[6] Cardo Jr., V.A., Mooney, J.W. and Stratigos, G.T. (1972) Iatrogenic Dental-Air Emphysema: Report of Case. Journal of the American Dental Association, 85, 144-147. http://dx.doi.org/10.14219/jada.archive.1972.0283

[7] Stillman, P.L., Ruggill, J.S., Rutala, P.J., Dinham, S.M. and Sabers, D.L. (1980) Students Transfering into an American Medical School. Remdiating Their Deficiencies. JAMA, 243, 129-133. http://dx.doi.org/10.1001/jama.1980.03300280027023

[8] Damore, D.T. and Dayan, P.S. (2001) Medical Causes of Pneumodiastinum in Children. Clinical Pediatrics (Phila), 40, 87-91. http://dx.doi.org/10.1177/000992280104000204

[9] Pierson, D.J. (1988) Pneumomediastinum. In: Murray, J.F. and Nadel, J.A., Eds., Textbook of Respiratory Medicine, WB Saunders, Philadelphia, 1795-1808.

[10] Quisling, R.W., Kangur, T.T. and Jahrsdoerfer, R.A. (1977) Otologic Complications Following the Use of a High- 
Speed Air Turbine Handpiece. Journal of the American Dental Association, 94, 895-897. http://dx.doi.org/10.14219/jada.archive.1977.0051

[11] Aragon, S.B., Dolwick, M.F. and Buckley, S. (1986) Pneumomediastinum and Subcutaneous Cervical Emphysema during Third Molar Extraction under General Anesthesia. Journal of Oral and Maxillofacial Surgery, 44, 141-144. http://dx.doi.org/10.1016/0278-2391(86)90198-9

[12] Nahieli, O., Neder, A. and Ashkelon, I. (1991) Iatrogenic Pneumomediastinum after Endodontic Therapy. Oral Surgery, Oral Medicine, Oral Pathology, Oral Radiology, 171, 618-619. http://dx.doi.org/10.1016/0030-4220(91)90373-K

[13] Stanton, D.C., Balasanian, E. and Yepes, J.F. (2005) Suncutaneous Cervicofacial Emphysema and Pneumomediastinum: A Rare Complication after a Crown Preparation. General Dentistry, 53, 122-124.

[14] Ely, E.W., Stump, T.E., Hudspeth, A.S., et al. (1993) Thoracic Complications of Dental Surgical Procedures: Hazards of the Dental Drill. American Journal of Medicine, 95, 456-465. http://dx.doi.org/10.1016/0002-9343(93)90327-L 